\title{
ARBITRAGEM, MEDIAÇÃO E CONCILIAÇÃ̃O: MÉTODOS ALTERNATIVOS DE SOLUÇÃO DE CONFLITOS
}

ARBITRATION, MEDIATION AND CONCILIATION: ALTERNATIVE CONFLICT SOLUTION

METHOD

Kairon Bruno FURNIEL ${ }^{1}$

ISSUE DOI: 10.21207/2675-0104.2017.677

\section{RESUMO}

A questão do grande número de processo no sistema judicial brasileiro, e por consequência, a demora exacerbada em dar uma sentença com resolução de mérito serão de grande relevância para o desenvolvimento do trabalho, inclusive eventuais aplicações práticas da arbitragem, mediação e conciliação. Consequentemente, também serão apresentadas as vantagens em se utilizar esses métodos de solução de conflitos. Este trabalho disserta sobre questões eminentemente relevantes e atuais no ramo do direito processual civil, devido à promulgação do Novo CPC, além das Leis n $13.129 / 2015$ (Lei da Arbitragem) e $n^{\circ} 13.140 / 2015$ (Lei da Mediação). E para cumprir o objetivo deste trabalho, a busca da solução dos problemas do Poder Judiciário, este artigo apresentará a Resolução 125/2010 do Conselho Nacional de Justiça (CNJ), que estabelece uma política de incentivo aos métodos consensuais do litígio, portanto promovendo a pacificação nas relações humanas.

Palavras-chave: Mediação. Conciliação. Arbitragem. Poder Judiciário.

\section{ABSTRACT}

The question of the large number of cases in the Brazilian judicial system, and consequently the exacerbated delay in giving a judgment with a resolution of merit, will be of great relevance for the devel-

\footnotetext{
${ }^{1}$ Discente da Faculdade de Direito de Franca (FDF), Franca/SP. Bolsista do Programa Interno de Iniciação Cientítica (PIBIC 2016-2017).
} 
opment of the work, including eventual practical applications of arbitration, mediation and conciliation. Consequently, the advantages of using these conflict resolution methods will also be presented. This paper discusses eminently relevant and current issues in the field of civil procedural law, due to the promulgation of the New CPC, in addition to Laws 13.129 / 2015 (Law of Arbitration) and 13.140 12015 (Law on Mediation). And in order to fulfill the objective of this work, the search for a solution of the problems of the Judiciary, this article will present Resolution 125/2010 of the National Council of Justice (NCJ), which establishes a policy to encourage the consensual methods of litigation, Pacification in human relations.

Keywords: Mediation. Conciliation. Arbitration. Judicial power.

\section{INTRODUÇÃO}

A função do Poder Judiciário é de manter a pacificação nas relações entre os cidadãos, aplicando as leis vigentes no país. Conforme leciona Carlos Lisboa (1999 p. 18):

A organização judiciária é um conjunto de normas e preceitos que regulam o arcabouço e a administração do Poder Judiciário em nosso País. É de responsabilidade do Poder Judiciário aplicar e interpretar a norma jurídica trazendo, assim, a paz ás relações humanas.

No entanto, a Justiça no Brasil sofre com a cultura do povo brasileiro, que tem o costume de recorrer ao sistema jurisdicional a qualquer litígio, dessa forma, abarrota o judiciário com processos que desencadeia outros fatores prejudiciais para as partes desse procedimento. Tais fatores são: a lentidão na prestação da tutela judicial pelo Estado, que consequentemente, acarreta a onerosidade excessiva do processo e a ineficácia da decisão. Por conseguinte, o Poder Judiciário não consegue de forma eficaz pacificar as relações humanas.

Para Velloso (1998, p.75), o principal problema do Judiciário é, sem dúvida, a morosidade da justiça. Acerca disso, afirma "[...] que não é possível que uma demanda se arraste por anos a fio. Isto gera descrença na justiça". Segue o autor dizendo que é preciso verificar as causas da lentidão da justiça, como: o aumento de processos decorrentes do aumento da cidadania, o número deficiente de juízes de $1^{\circ}$ grau, o desaparelhamento do apoio administrativo no $1^{\circ}$ grau e as leis processuais: excesso de formalismo e sistema irracional de recurso; bem como apontar propostas de solução. 
Com esses problemas apontados pode ser percebido que não houve uma preparação anterior do Poder Público, que deixou de fazer alterações, antecipadamente, que beneficiassem o andamento dos processos por via judicial. Assim, após ser constatado o grande número de demandas que assombravam o sistema jurisdicional brasileiro, no ano de 2015 trouxe modificações estruturais no Código de Processo Civil a fim de tornar mais célere à solução dos conflitos de interesse no judiciário.

Desta maneira, durante essas alterações, os institutos da Arbitragem, Mediação e Conciliação receberam uma nova abordagem jurídica. As novidades trazidas dentro desse código foram com a finalidade de tornar tais procedimentos mais práticos, ipso facto, sendo mais utilizados pelos cidadãos brasileiros. No mesmo ano, esses institutos, também, sofreram alterações nas legislações específicas, logo, a Lei 9.307/96 foi substituída pela Lei 13.129/2015 (Lei da Arbitragem), e a Mediação recebeu uma regulamentação através da Lei n ${ }^{\circ} 3.140 / 2015$.

\section{2}

ARBITRAGEM, MEDIAÇÃO E CONCILIAÇÃO

A palavra "arbitragem" tem origem do latim "arbiter", e é recorrente sua utilização na linguagem jurídica para significar procedimento na solução de litígios. Tem como definição o instituto pelo qual as partes confiam em árbitros para solucionarem seus litígios. Portanto, a arbitragem é uma solução alternativa de conflitos mais simples e objetiva, por vezes acordados entre as partes e outra imposta obrigatoriamente pela lei, visa uma resolução das controvérsias mais célere e eficaz do que o processo judicial, e tem como requisitos a escolha de um árbitro pelas partes, sem interferência do Estado, sendo que sua sentença assumiria a mesma eficácia de uma sentença judicial.

Para Carlos Alberto Carmona e outros autores ao invés de denominar a arbitragem como um método alternativo de solução de conflitos deveria ser chamado, de maneira mais correta, de meio adequado de solução de controvérsias.

O fato é que, se não constituísse uma alternativa às partes, seria inconstitucional, posto que houvesse imposição da solução por intermédio 
da arbitragem, o que fere o princípio da inafastabilidade da tutela insculpido no art. $5^{\circ}, \mathrm{XXXV}$, da Constituição Federal2.

Enquanto que a mediação, além de integrar parte do processo, também pode ser definida como uma arte e técnica de resolução de conflitos intermediária, consequentemente, tal instituto é um método de pacificação social, em que pode ser utilizado nas relações humanas que estão em conflitos, no qual atuam um terceiro mediador (agente público ou privado). A definição de mediação está expressa no parágrafo único do art. $1^{\circ}$ da Lei $\mathrm{n}^{\circ}$ 13.1403, conhecida também como Lei da Mediação. A Conciliação é um processo técnico em que terceiro imparcial atua de forma a auxiliar as partes a encontrar soluções que atendem seus interesses, dessa forma extinguindo o conflito que ali existia.

A diferença entre eles, por conseguinte, consiste em que o conciliador atuará preferencialmente em casos nos quais não houver vínculo anterior, em contrapartida o mediador atuará preferencialmente nos casos que existir vínculo anterior entre as partes. Por fim, a competência na conciliação, o terceiro poderá sugerir soluções, no entanto não poderá intimidar as partes para que aceitem tais condições, já na mediação o terceiro auxiliará os interessados a compreenderem os interesses da outra parte, para que possam chegar a uma solução consensual por si próprios, dessa forma é vedado aos mediadores indicar soluções para a resolução do conflito.

Os objetivos desses métodos são semelhantes, em geral são o de transformar o processo judicial que é demorado e desgastante às partes em uma solução mais célere e efetiva aos interesses tanto do autor como o do réu. Assim, os mediadores, como os conciliadores, tentam orientarem e auxiliar, através de conversas, obter ao fim um acordo entre as partes.

Importante ressaltar que as atuações do mediador e conciliador deverão ser de acordo com a delimitação do Código de Processo Civil e outras leis esparsas, por exemplo, a Lei da Mediação, podendo ser diferente a abordagem das competências desses terceiros.

Conforme explicado por CAHALI, Francisco José (2012, p.49):

\footnotetext{
${ }^{2}$ Constituição Federal, art. 5, XXXV - "a lei não excluirá da apreciação do Poder Judiciário lesão ou ameaça de direito;".

${ }^{3}$ Lei $13.140 / 2015$, art. $1^{\circ}$, parágrafo único - "considera-se mediação a atividade técnica exercida por terceiro imparcial sem poder decisório, que, escolhido ou aceito pelas partes, as auxilia e estimula a identificar ou desenvolver soluções consensuais para a controvérsia.".
} 
O conciliador, seja Juiz ou não, fica na superfície do conflito, sem adentrar nas relações intersubjetivas, nos fatores que desencadearam o litígio, focando mais as vantagens de um acordo onde cada um cede um pouco, para sair do problema. Não há preocupação de ir com maior profundidade nas questões subjetivas, emocionais, nos fatores que desencadearam o conflito, pois isso demandaria sair da esfera dogmática jurídica, dos limites objetivos da controvérsia.

Os institutos citados tornaram importantes, portanto, devido à possibilidade de solucionarem o problema do Poder Judiciário, desencadeador de uma série de outros malefícios para o processo judicial. Porém, para que os cidadãos brasileiros se utilizem da arbitragem, mediação e conciliação é preciso que estes apresentem vantagens sobre o procedimento jurisdicional.

\section{VANTAGENS DESSES MÉTODOS ALTERNATIVOS DE RESOLUÇÃO DE CONFLITOS}

As vantagens da arbitragem podem ser elencadas em: celeridade e sigilo do procedimento; e segurança jurídica da sentença. Enquanto que a mediação e conciliação apresentam os seguintes benefícios: celeridade, sigilo e economicidade processual; e segurança jurídica da sentença.

Para se falar da celeridade dentro do procedimento arbitral, é necessário demonstrar a forma em que os prazos para solucionar a controvérsia ocorra dentro da Arbitragem. Conforme o inciso III do art.11 da Lei da Arbitragem4, em respeito ao princípio da autonomia da vontade, as parte em conjunto com o árbitro poderão delimitar um prazo razoável para a solução do litigio. Este direito trata-se de uma faculdade para as partes, e caso as partes não acordem sobre o tempo para resolução do conflito, a mesma lei, no art.235, estabeleceu que fosse de 6 meses o prazo para o juiz proferir sua decisão, tendo a possibilidade de ser prorrogado por comum acordo, $\S$ $2^{\circ}$ do art. 236. A contagem desse prazo dar-se-á através da instituição da

\footnotetext{
${ }^{4}$ Lei 9.307/96, art.11 - "poderá, ainda, o compromisso arbitral conter:

III - o prazo para apresentação da sentença arbitral;".

${ }^{5}$ Lei 9.307 , art. 23, caput - "a sentença arbitral será proferida no prazo estipulado pelas partes. Nada tendo sido convencionado, o prazo para a apresentação da sentença é de seis meses, contado da instituição da arbitragem ou substituição do árbitro.".

${ }^{6}$ Lei 13.129/2015, art. 23, $\S 2^{\circ}$ - "as partes e os árbitros, de comum acordo, poderão prorrogar o prazo para proferir a sentença arbitral.".
} 
arbitragem ou da substituição do árbitro. Os prazos arbitrais não se sujeitam aos prazos do CPC.

Outro ponto importante para que seja preservada a celeridade da arbitragem é a irrecorribilidade da decisão arbitral. Neste sentido, Uadi Lamego BULOS (1998, p.79) analisa:

[...] o que justifica, todavia, a irrecorribilidade consagrada é uma profunda necessidade social de evitar a perduração dos litígios, tanto mais quando, sendo o árbitro pessoa de confiança das partes, muito mais difícil a existência da má-fé, e, sendo técnico ou perito, mais raro erro.

Assim, pode ser percebido que com a não possibilidade de alongar-se o processo com recursos, diferentemente do que ocorre no processo judicial que permite a concessão de intermináveis recursos tornando o processo demorado.

O sigilo do procedimento arbitral está relacionado com a não incorporação do princípio da publicidade na arbitragem. Destarte, as audiências terão caráter sigiloso, e as informações que forem divulgadas ali deverão se manter confidenciais, não podendo ser vazadas pelo árbitro ou pela sua equipe, como também, pelas partes e seus procuradores. Desta maneira, os atos realizados durante as sessões não serão públicos, mas privados, sem acesso de terceiros às informações desse procedimento.

A seguridade jurídica da arbitragem está associada diretamente à exigibilidade de fundamentação da sentença. Pois, ao árbitro fundamentar sua decisão possibilita que a parte vencida possa analisar se os motivos que foram considerados para decidir segue o que havia sido convencionado pela parte, seja de direito ou equidade conforme autoriza o artigo $2^{\circ}$ da Lei $13.129 / 2015^{7}$. A exigibilidade de fundamentação trata-se de requisitos formais obrigatórios para a validade da sentença. Enfim, a segurança também pode ser obtida por a sentença arbitral ser considerado título executivo judicial, dando o direito à parte vencedora pleitear ao órgão judiciário a execução da decisão do árbitro. Outro ponto relevante para a segurança é a escolha de árbitros especialistas no assunto do objeto do litígio.

Observação importante a ser feita ao analisar as vantagens da arbitragem, diferentemente do que ocorre na Mediação e Conciliação, é a de que não se pode atribuir a característica de ser um processo econômico,

\footnotetext{
${ }^{7}$ Lei 13.129/2015, art. $2^{\circ}$, caput - "a arbitragem poderá ser de direito ou equidade, a critério das partes.".
} 
pois, o valor final do procedimento está relacionado aos custos com a contratação dos árbitros, e não a rapidez na solução do conflito de interesses.

Enquanto que a agilidade da tutela na mediação e conciliação é preciso de antemão informar que esses institutos podem ser realizados tanto extrajudicialmente quanto judicialmente. Na extrajudicial, está relacionado com a possibilidade de as partes convencionarem sobre os prazos para a solução do conflito. No judicial, a mediação ou conciliação são realizadas em audiências preliminares, sendo que, não é necessário entrar nas outras fases processuais, por exemplo, a fase probatória. Em decorrência dessa rapidez, a decisão do mediador ou conciliador torna mais econômico do que a dos processos julgados pelo Estado.

O sigilo do procedimento envolvendo esses institutos está associado à incorporação do princípio da confidencialidade, o qual estabelece que as informações sobre as audiências ou qualquer outro ato praticado durante as sessões de mediação e conciliação devam manter-se em caráter sigiloso. Por conseguinte, os mediadores e conciliadores, como também suas equipes; e as partes com seus respectivos procuradores não podem divulgar e depor sobre informações que ocorram dentro desses procedimentos. Com relação à confidencialidade no processo, a juíza Ellen Gracie NORTHFLEET (1994, p. 235), do Supremo Tribunal Federal, afirma que:

O clima de informalidade e confidencialidade das sessões favore-
cem o esclarecimento de situações que talvez não aflorassem na
sala das audiências. O diálogo que se estabelece entre as partes é
mais verdadeiro porque envolve a inteireza de suas razões e não
apenas aquelas que poderiam ser deduzidas com forma e figura de
juízo.

Na mediação e conciliação, a seguridade jurídica para a sentença associa-se a própria natureza da decisão do mediador ou conciliador, desta maneira, a sentença será convertida a termo e homologada, constituindo título executivo judicial, conforme inc.III do art. 515 do CPC. Isto é, caso a parte vencida não venha a cumprir a decisão dos mediadores e conciliadores, a parte vencedora poderá pleitear ao Poder Judiciário, a fim de que esta se utilize de seu poder de polícia, assim, coagindo a perdedora a cumprir com sua obrigação.

A economicidade dentro dos procedimentos mediatório e conciliatórios é consequência da celeridade na prestação da tutela jurisdicional por partes desses institutos. Isso porque, nos processos judiciais que não 
ocorre a decisão convencional pelas partes o processo pode alongar-se durante anos, e a cada dia a mais que se demora em solucionar o litigio aumenta as custas processuais, como também, a cada instauração de recurso que com antecedência deverá ser depositado o preparo.

\section{$4 \quad$ ALTERAÇÕES DA LEGISLAÇÃO SOBRE OS INSTITUTOS}

Com a conceituação e demonstração da vantagem pode ser mostrada a importância desses métodos de resolução de conflitos para a solução dos problemas do Poder Judiciário. Destarte, nos seguintes parágrafos dará relevância as mudanças feitas pelas as legislações sobre esses institutos para que estes métodos tornassem viáveis. Primeiramente a legislação que aborda ambos os institutos é o CPC de 2015 que foi promulgada revogando o código de 1973. Dessa forma, uma das mudanças desse ordenamento jurídico foi reconhecer esses métodos de resolução de conflito. A mediação e conciliação no art. $3^{\circ}, \S 2^{\circ} 8$ deste código foi estabelecido que ambos os institutos devessem ser apreciados pelo órgão jurisdicional. A arbitragem foi instituída pelo art. $3^{\circ} ; \S 1^{\circ} 9 \mathrm{e}$ reafirmado a possibilidade de seu uso no art. $42^{10}$, concedendo a instituição de juízo arbitral pelas partes.

Contudo é importante ressaltar que o Código de Processo Civil é utilizado dentro da arbitragem de forma subsidiária, isto é, auxilia no que a lei desse instituto deixar de forma obscura ou lacunar. Assim, foi por meio da Carta Arbitral que promoveu a harmonização entre essas duas legislações, de forma que o árbitro pudesse se comunicar com o juiz estatal, a fim de que o último auxiliasse na concessão de pedidos liminares, cautelares e antecipações de tutela, além de requerer à autoridade judiciária que conduza testemunha renitente, conforme inciso IV do art.237 do CPC11.

\footnotetext{
${ }^{8}$ Código de Processo Civil de 2015, art. $3^{\circ}, \S 2^{\circ}$ - “o Estado promoverá, sempre que possível, a solução consensual dos conflitos.".

${ }^{9}$ Código de Processo Civil de 2015, art. $3^{\circ}, \S 1^{\circ}$ - "é permitida a arbitragem, na forma da lei.".

${ }^{10}$ Código de Processo Civil de 2015, art. 42 - "as causas cíveis serão processadas e decididas pelo juiz nos limites de sua competência, ressalvado às partes o direito de instituir juízo arbitral, na forma da lei.".

${ }^{11}$ Código de Processo Civil de 2015, art. 237 - "será expedida carta:

IV - arbitral, para que o órgão do Poder Judiciário pratique ou determine o cumprimento, na área de sua competência territorial, de ato objeto de pedido de cooperação judicial formulado por juízo arbitral, inclusive os que importem efetivação de tutela provisória.".
} 
Desde que entrou em vigor o Código de Processo Civil de 2015 foi definido que seria requisito obrigatório da Petição Inicial constar se o autor teria interesse na realização da audiência de conciliação ou mediação (inc. VII do art. 31912). No caso do réu demonstrar disponibilidade em chegar a uma decisão consensual caberá ao oficial de justiça cumprir o mandato de intimação para que a outra parte compareça a uma audiência preliminar com a finalidade de conciliar ou mediar à relação conflituosa entre as partes, de acordo com art. 250 inc. IV. Por fim, o réu depois de intimado poderá enviar um protocolo para pedir o cancelamento da audiência de conciliação ou mediação caso não se interesse pela solução alternativa do conflito. Importante ressalta que durante o período destinado a autocomposição os prazos serão suspensos.

Consequentemente, para que não ocorra a audiência de conciliação e mediação é necessário que ambas as partes, de forma expressa, demonstrem desinteresse à audiência preliminar ou em casos que o conflito não admita a autocomposição, dessa forma, se nenhuma dessas duas condições ocorrerem à audiência preliminar terá caráter obrigatório.

A Lei da Mediação (Lei 13.140/2015) teve como destaque, além daqueles já apresentados, a possibilidade de o procedimento desse instituto ser tanto judicial quanto extrajudicial. O procedimento extrajudicial, isto é, aquele que tramita fora do juízo, iniciasse após o convite de instaurar a mediação, que pode ser feito por qualquer meio de comunicação, devendo constar o escopo, além da data e o local. Nesse procedimento deverá haver uma previsão contratual estipulando, por exemplo, o local da primeira reunião, critérios de escolhas do mediador ou equipe de mediação, bem como a penalidade em casos de não comparecimento nas sessões, também nessa previsão contratual poderão as partes convencionar em não iniciar um procedimento arbitral ou judicial durante um período acordado entre elas, sendo que o juiz ou árbitro suspenderam o curso da ação ou arbitragem até ao fim dessa condição.

Enquanto que no procedimento judicial, ou seja, aquele que corre perante aos órgãos jurisdicionais para a realização da mediação caberá à criação de centros judiciários de solução consensual de conflitos. Nesse procedimento as partes deverão ser assistidas por advogados ou defensores públicos, além de que a mediação dentro dos órgãos judiciários deverá ser

\footnotetext{
${ }^{12}$ Código de Processo Civil de 2015, art. 319 - "a petição inicial indicará:

VII - a opção do autor pela realização ou não de audiência de conciliação e de mediação.".
} 
concluída em sessenta dias, salvo se as partes convencionarem pela prorrogação. Se houver acordo os autos serão encaminhados ao juiz que arquivará o processo e homologará o acordo.

As principais alterações da legislação específica da arbitragem (Lei 13.129/2015) teve a possibilidade de utilização desse instituto pela a Administração Pública direta ou indireta, de acordo com art. $1^{\circ} ; \S 1^{\circ 13}$, sendo necessário que o direito em questão seja patrimonial e disponível. No entanto, importante ressalvar que esse direito é facultativo, ou seja, não é obrigatório tal órgão dirimir seus conflitos por via arbitral. Esse artigo trouxe divergências doutrinárias, que abaixo será exposto às duas mais significantes para esse tema.

A primeira teoria afirma que o Poder Público poderia utilizar-se da arbitragem, desde que respeitado o principio da legalidade, isto é, que só poderia convencionar o juízo arbitral se estiver expresso na lei que tal matéria poderia se submeter à convenção arbitral. Essa teoria é adotada por muitos doutrinadores, como por exemplo, os ensinamentos de Hely Lopes Meirelles (2016, p.93) e Celso Antônio Bandeira de Mello (2010, p.99105), respectivamente:

O administrador Público está, em toda a sua atividade funcional, sujeito aos mandamentos da lei e às exigências do bem comum, e deles não se pode afastar ou desviar, sob pena de praticar ato invalido e expor-se a responsabilidade disciplinar, civil ou criminal, conforme o caso. (...) Na Administração Publica não há liberdade nem vontade pessoal. Enquanto na administração particular é licito fazer tudo que a lei não proíbe, na Administração Publica só é permitido fazer o que a lei autoriza.

Este é o principio capital para a configuração do regime jurídicoadministrativo. Justifica-se, pois, que seja tratado - como o será com alguma extensão e detença (...) em suma: a consagração da ideia de que a Administração Publica só pode ser exercida na conformidade da lei e que, de conseguinte, a atividade administrativa é atividade sublegal, infralegal, consistente na expedição de comandos complementares à lei. (...) 'o principio da legalidade, no Brasil, significa que a Administração nada pode fazer senão o que a lei determina. Ao contrario dos particulares, os quais podem fazer tudo o que a lei não proíbe a Administração só pode fazer o que a lei antecipadamente autorize'.

Enquanto que a segunda corrente entende-se que o Poder Público pode recorrer à arbitragem independente de que matéria querem submeter

${ }^{13}$ Lei $13.129 / 2015$, art. $1^{\circ}, \S 1^{\circ}$ - "a administração pública direta e indireta poderá utilizar-se da arbitragem para dirimir conflitos relativos a direitos patrimoniais disponíveis.". 
à convenção arbitral, esteja expressamente permitido em lei ou que a lei não proíba, bastando ser um direito patrimonial disponível. Em suma, as duas teorias diferem enquanto a utilização do principio da legalidade.

Dessa forma, ao analisar o $\S 1^{\circ}$ do artigo $1^{\circ}$ da lei $n^{\circ} 13.129$ de 2015, no qual fala da utilização da arbitragem pela Administração Pública não restringe a utilização desse método alternativo para resolução de conflitos em obediência ao princípio da legalidade. Porém, esse princípio está expresso no artigo 37 da Constituição Federal14, assim ao conciliar esses dois artigos levando em conta à hierarquia das legislações, é passível concluir-se que a Administração Pública pode sim recorrer a arbitragem, porém, desde que respeitados o princípio da legalidade.

Ainda em relação à administração pública direta, o § $2^{\circ}$ do artigo $1^{\circ} 15$ para não haver confusões de quem poderia celebrar a convenção arbitral deixou claro quais órgãos ou autoridades competentes poderiam utilizar-se desse direito, assim expôs, que são as mesmas que tem competência para a realização de acordos ou transações. Por conseguinte, tanto a administração pública direta ou indireta no que constar a convenção de arbitragem somente poderá ser de direito e respeitará o princípio da publicidade, exceção à privacidade dos juízos arbitrais.

Ainda essa legislação concedeu ao instituto da arbitragem o poder de interromper o prazo da prescrição, com ressalvas de que mesmo se a arbitragem for extinta por falta de jurisdição a prescrição retroagirá a data de requerimento da instauração da arbitragem. Por fim, trouxe um novo capítulo sobre as tutelas cautelares e de urgência dentro da arbitragem, possibilitando a utilização deles dentro do procedimento arbitral.

Contudo, após apresentado os métodos alternativos de solução do conflito e demonstrado sua importância na resolução dos problemas do Poder Público, bem como as alterações sofridas nas legislações dos institutos da arbitragem, mediação e conciliação, agora será exibido a Resolução 125 de 2010 do Conselho Nacional de Justiça. Essa resolução teve como finalidade instruir os partícipes da jurisdição estatal a como se comportar mediante a esses métodos alternativos.

\footnotetext{
${ }^{14}$ Constituição Federal, art. 37, caput - "a administração pública direta e indireta de qualquer dos poderes da União, dos Estados, do Distrito Federal, e dos municípios obedecerá aos princípios da legalidade, impessoalidade, morosidade, publicidade e eficiência".

${ }^{15}$ Lei $13.129 / 2015$, art. $1^{\circ}, \S 2^{\circ}$ - "a autoridade ou o órgão competente da administração pública direta para a celebração de convenção de arbitragem é a mesma para a realização de acordos ou transações.".
} 
Dessa forma, a Resolução do CNJ trouxe uma série de medidas para desenvolver uma rede constituída por órgãos do Poder Judiciário e por entidades públicas ou privadas, a fim de organizar um programa para promover ações de incentivo à autocomposição e à pacificação social. Desse modo, para o desenvolvimento dessa rede é importante que o CNJ crie o conteúdo programático mínimo e ações voltadas à capacitação em métodos consensuais de solução de conflitos para magistrados, servidores, conciliadores, mediadores, e outros facilitadores da solução consensual, além de regulamentar com um código de ética para esses auxiliares da conciliação, mediação, e demais procedimentos que tenham como finalidade a busca do consenso entre as partes. Também coube ao Conselho Nacional de Justiça incentivar os magistrados a buscar uma solução consensual entre as partes, considerando esses métodos nas promoções e remoções de magistrados como critério de merecimento.

Para o cumprimento do objetivo do CNJ e para o desenvolvimento da rede, essa resolução estabeleceu que se devesse buscar uma cooperação de outros órgãos como a Ordem dos Advogados do Brasil, Defensoria Publica e Ministério Público incentivando a atuação deles nos Centros de Solução de Conflitos e Cidadania. Além disso, junto aos órgãos públicos competentes e instituições de ensino público ou privado com a finalidade de incentivar o surgimento da cultura da solução pacífica dos conflitos, também inserir dentro das Escolas de Magistratura módulo voltado a métodos de solução consensual de conflitos.Enfim, realizar junto às empresas públicas e privadas, como também, agências reguladoras de serviços públicos, a fim de instaurar praticas autocompositivas e desenvolver acompanhamento estatísticos, conferindo selo de qualidade conforme a obtenção dos resultados.

Desta maneira, compete ao CNJ promover ações de incentivo a métodos alternativos para a solução dos litígios e a pacificação social através do uso da conciliação e mediação. No parágrafo único do art. $1^{\circ}$ dessa resolução incumbiu aos órgãos jurisdicionais oferecer e orientar os cidadãos com informações e incentivo a utilização principalmente da mediação e conciliação ou o uso até mesmo de outros meios consensuais para uma rápida e eficaz solução dos conflitos.

A Resolução do CNJ N${ }^{\circ} 125 / 2010$ estabeleceu que os Tribunais criassem Núcleos Permanentes de Método Consensuais de Solução de Conflitos com estas principais atribuições: desenvolver a Política Judiciária de tratamento adequado dos conflitos de interesse, como também, ao analisar os resultados obtidos tentar chegar numa decisão consensual entre 
as partes para aperfeiçoar a aplicação da autocomposição. Também foi atribuído aos Tribunais a instalação de Centros Judiciários de Solução de Conflitos e Cidadania para a realização das sessões de mediação e conciliação que estejam a cargo dos conciliadores e mediadores, dos órgãos por eles abrangidos. Por fim, para uma melhor prestação na conciliação das partes, é uma função dos Tribunais promover a capacitação, treinamento e atualização permanente dos magistrados, servidores, conciliadores e mediadores nos métodos consensuais de resolução de conflitos.

\section{$5 \quad$ CONCLUSÃO}

Conclui-se, assim, que esses métodos têm a capacidade para resolver os problemas apresentados pelo Poder Judiciário, além de apresentar vantagens para que as partes recorram à arbitragem, mediação e conciliação. Além de que, em 2015, com as promulgações das legislações, que alteraram beneficamente tais institutos, deram uma relevância, justificando assim a escolha deste tema. O presente artigo, ainda mencionou a Resolução 125/2010 do CNJ, que tem grande importância para a pacificação das relações humanas, ao incorporar uma politica de incentivo aos métodos consensuais de resolução de conflitos de interesses, buscando uma mudança na cultura conflituosa da sociedade brasileira.

\section{REFERÊNCIAS BIBLIOGRÁFICAS}

BERALDO, Leonardo de Faria. Curso de Arbitragem: nos termos da Lei n ${ }^{\circ}$ 9.307/96. São Paulo, Atlas, 2014.

CACHAPUZ, Rozane da Rosa. Arbitragem: alguns aspectos do processo e procedimento na lei $\mathrm{n}^{\circ}$ 9.307/96. LED - Editora de Direito, 2000

CAHALI, Franscisco José. Curso de Arbitragem. $2^{\mathrm{a}}$ ed. São Paulo, RT, 2012.

CARMONA, Carlos Alberto. Arbitragem e Processo: um Comentário á Lei 9.307/96. São Paulo, Malheiros, 1998.

CARMONA, Carlos Alberto. A Arbitragem no Processo Civil Brasileiro. Malheiros, 1993.

DIDIER JR, Fredie. Curso de direito processual civil: introdução ao direito processual civil, parte geral e processo de conhecimento. Salvador. Jus Podium, 2015. 
FURTADO, Paulo; BULOS, Uadi Lammêngo. A lei da Arbitragem Comentada. São Paulo: Saraiva, 1998.

LACERDA, Belizário Antônio. Comentários à Lei de Arbitragem. Del Rey, 1998

LEVY, Fernanda R. Lourenço; Guarda de filhos: os conflitos no exercício do poder familiar. São Paulo, Atlas, 2008.

LISBOA, Carlos. Manual do árbitro. São Paulo: Saraiva,1999.

MEIRELES, Hely Lopes. Direito Administrativo Brasileiro. Malheiros. Edição 42, 2016

MELLO, Celso Antônio Bandeira. Curso de Direito Administrativo. Malheiros. Edição 27, 2010

MUNIZ, Joaquim de Paiva. A arbitragem ao alcance de todos - Cartilha de arbitragem. Rio de Janeiro, OAB-RJ, 2004.

NORTHFLEET, Ellen G. Novas fórmulas para resolução de conflitos. In: TEIXEIRA, Sálvio de Figueiredo. O judiciário e a constituição. Brasília: Saraiva, 1994.

REALE, Miguel. Crise da Justiça e Arbitragem. Revista de Arbitragem e Mediação. São Paulo: Revista dos Tribunais, ano 2, n. 5, abr./jun. 2005, p. 13.

ROCHA, Caio Cesar; Vieira, SALOMAO, Luis Felipe. Arbitragem e Mediação, a reforma da legislação brasileira. Editoras Atlas, Edição 1, 2015

ROQUE, Sebastião José. Arbitragem a Solução Viável. Ícone Editora. Edição 2, 2009.

SCAVONE JUNIOR, Luiz Antônio. Manual de Arbitragem. São Paulo, Revista dos Tribunais, 2014.

THEODORO JR, Humberto. Código de Processo Civil. Forense, 2003.

THEODORO, Júnior, Humberto et al. Novo CPC: Fundamentos e sistematização. Rio de Janeiro: Forense, 2015

VASCONCELOS, Carlos Eduardo. Mediação de Conflitos e Praticas Restaurativas. Editora Método, 2008

VELLOSO, Carlos Mário da Silva. Do Poder Judiciário: como torná-lo ágil e dinâmico-efeito vinculante e outros temas. Disponível em: <http://bibliotecadigital.fgv.br/ojs/index.php/rda/arti-

cle/viewFile/47162/45631>. Acesso em: 27 de jul. de 2017

WARAT, Luis Alberto. O ofício do mediador. Florianópolis, Habitus, 2001. 